\title{
Educação e surdez: o papel do ensino na visão de professores*
}

\section{Education and deafness: the teaching in the teachers' vision}

\author{
Ana Dorziat**
}

\begin{abstract}
RESUMO
O ensino de surdos foi, por longo período, baseado num modelo médico em que prevaleciam técnicas fonoaudiológicas para o desenvolvimento da expressão oral. Os aspectos relacionados ao ensino foram sempre relegados a segundo plano. Atualmente, com a valorização da língua de sinais nas escolas, os professores mudam de papel, de terapeutas para educadores, e, nessa mudança, carregam consigo concepções de ensino que vão influir, direta ou indiretamente, sobre suas práticas. Entendendo a importância de fomentar reflexões educacionais mais profundas na área, desenvolvi um estudo em uma escola pública de surdos, buscando investigar, a partir de entrevistas, as concepções de ensino externalizadas pelas professoras. Os dados revelaram noções pragmáticas de ensino, evidenciando a necessidade de uma profunda reorganização conceitual, filosófica e prática nessa área.
\end{abstract}

Palavras-chave: ensino, surdez, professor.

\begin{abstract}
The teaching of the deaf has long been based on a medical model in which phonoaudiological techniques to develop oral expression prevailed. The aspects related to teaching have always been relegated to second plan.

* O estudo é um recorte do trabalho de tese da autora, financiado pelo CNPq/Capes.

${ }^{*}$ Doutora em Educação pela Universidade Federal de São Carlos/UFSCar. Professora da Universidade Federal da Paraíba-UFPB/Programa de Pós-Graduação em Educação-PPGE. e-mail:
\end{abstract} dorziat@uol.com.br 


\begin{abstract}
Nowadays, due to the valorization of sign language in schools, teachers change their roles from therapists to educators, and with this change they carry on teaching concepts that will influence their practices directly or indirectly. Understanding the importance of stimulating deeper educational reflections in this field, I have developed a study in a public school for the deaf, trying to investigate, through interviews, the teaching concepts externalized by the teachers. The information collected revealed pragmatic teaching notions, evidencing the need of a profound conceptual, philosophical and practical organization in this field.

Key-words: teaching, deafness, teacher.
\end{abstract}

\title{
Introdução
}

As escolas voltadas para alunos surdos têm enfrentado grandes dificuldades em se organizarem como espaços, primordialmente, de ensino e aprendizagem. Essa dificuldade é produto de uma visão clínico-reabilitadora, em que os surdos, considerados portadores de uma patologia, deveriam aprender a expressar-se oralmente, se quisessem vislumbrar alguma participação na sociedade. Nesse contexto, eram desconsideradas discussões que contemplassem as questões pedagógicas (para quem ensinar; onde ensinar; o que ensinar; como ensinar; quando ensinar; para que ensinar).

Em minha experiência profissional, tendo os surdos como populaçãoalvo, esse tipo de formação foi marcante. Por um período considerável, a prática docente com crianças surdas, o trabalho de assessoria pedagógica a uma escola de surdos e as disciplinas ministradas em curso de formação de professores de surdos foram norteados por essa concepção. Apesar de, teoricamente, considerar esse o caminho mais apropriado, no confronto com a prática, experimentava um constante sentimento de insatisfação, devido ao fraco desempenho acadêmico dos alunos em noções básicas como ler, escrever e contar, sem falar no desenvolvimento da habilidade mais exigida: falar oralmente.

O surgimento da Comunicação Total, que pregava a utilização de todas as formas possíveis de comunicação, tendo como linha mestra o uso de sinais colocados na estrutura da língua portuguesa (Português Sinalizado), trouxe novas perspectivas de desenvolvimento na escolaridade dos surdos. Embora os efeitos positivos trazidos pelo estabelecimento de uma comunicação mais 
fluente tenham sido inegáveis, passado o primeiro momento de euforia e sempre em contato com as novas produções na área, pude constatar que, além de poucos avanços em aquisição de leitura e de escrita, a prática baseada na Comunicação Total era tão somente uma forma travestida de Oralismo. Com as críticas à Comunicação Total, emergia a concepção bilíngüe que aconselhava, basicamente, o uso da língua de sinais na sua forma genuína, como primeira língua, e a aprendizagem da língua majoritária ou oficial (no caso do Brasil, a língua portuguesa), como segunda língua.

Num primeiro momento, o aspecto lingüístico foi o mais considerado nas explicações sobre o Bilingüismo. Atualmente, é possível perceber que a mudança de uma metodologia/filosofia oralista para uma visão bilíngüe não constitui tarefa simples. Subjacente ao uso da língua de sinais, há um novo modo de conceber a surdez e suas implicações sociais.

Com o Bilingüismo, a urgência em prover o surdo da expressão oral e/ ou gestos artificiais (Português Sinalizado), como critério básico para seu desenvolvimento cognitivo, não tinha mais razão de ser. Isso não significava que a linguagem passava a ter menos importância. Pelo contrário, foi-lhe dada a devida importância, na medida em que ela deixou de ser vista como articulação oral e/ou gestual mecânica, para ser considerada meio de apreensão e expressão, por meio do qual as pessoas apropriam-se do mundo tal qual ele se lhes apresenta.

No entanto, as implicações educacionais da surdez precisam ser consideradas, superando o momento atual, em que a atenção de muitos profissionais envolvidos no ensino de surdos, numa perspectiva bilíngüe, tem ficado restrita aos componentes lingüísticos de forma isolada. Tem-se deixado de lado o desvendamento do fenômeno na sua totalidade, e, em conseqüência disso, diferentes posturas pedagógicas terminam convivendo no processo pedagógico, de forma acrítica, reproduzindo no cotidiano de sala de aula estratégias consideradas eficazes no ensino de pessoas ouvintes ou mesmo práticas adaptadas aos surdos, sem uma base epistemológica que dê sentido às ações.

Essas práticas têm me inquietado, suscitando o seguinte questionamento: que concepções de ensino têm norteado o trabalho de professores de surdos?

Tendo por base essa questão, desenvolvi a presente pesquisa, com o objetivo de analisar as concepções de ensino de professores de surdos, de uma escola pública voltada exclusivamente para o ensino dessa população. Essas concepções foram externalizadas em entrevistas, que enfocaram duas questões:

- Qual a função da instituição escola?

- Qual a função da escola de surdos? 


\section{Fundamentação teórica: o ensino numa perspectiva sócio-histórica}

Nos últimos anos, as experiências educacionais cognitivistas, que buscam atrelar o ensino e as estratégias educacionais a um ponto de vista biológico, universal e neutro, parecem predominar no ensino.

Essa visão de ensino não se coaduna com a visão de homem, como ser historicamente construído. Segundo LEONTIEv (1978), um estudo da interação do meio exterior e dos diferentes organismos que não leve em conta a própria natureza desses organismos "é uma abstração absolutamente ilegítima" (p. 159). O que é o meio para o organismo e como este meio se manifesta para ele depende da própria natureza do organismo em questão, das transformações que ele pode sofrer sob a influência do meio. É isso que assegura a sucessão das gerações, o movimento da evolução filogenética (LEONTIEv, 1978). Para ele, as explicações sobre as particularidades específicas do indivíduo humano, a sua atividade e o seu psiquismo devem ser consideradas tendo em vista as relações entre estas especialidades adquiridas no desenvolvimento da sociedade.

A abordagem de uma Pedagogia histórico-crítica, em consonância com as bases da Psicologia sócio-histórica, segue esse caminho para fundamentar as questões de ensino. Ela aceita a tese de que os estágios de desenvolvimento infantil possuem um conteúdo preciso em sua atividade principal e uma certa sequiência no tempo. Os aspectos de cada estágio não são imutáveis e dados de uma vez por todas. Cada nova geração e cada novo indivíduo, pertencente a uma certa geração, possui determinadas condições já estabelecidas de vida, que produzem também o conteúdo de sua atividade possível, qualquer que seja ela. Tratando dessa questão, LEONTIEv (1988) afirma que, embora se note um certo caráter periódico no desenvolvimento da psique infantil, o conteúdo dos estágios não é, de forma alguma, independente das condições concretas em que ocorre o desenvolvimento. Segundo ele, é dessas condições que o conteúdo depende primariamente. A atividade engendra o desenvolvimento e é engendrada por ele.

Nessa direção, VYGOTSKI (1991) aponta para a necessidade de incluir as condições históricas concretas no processo de determinação dos princípios educacionais. Para ele, o desenvolvimento da criança não pode ser compreendido por meio do estudo do indivíduo. Deve ser examinado também o mundo social externo em que a vida individual se desenvolve. Procurando explicitar esses pressupostos, GALLIMORE e THARP (1996) afirmam que as habilidades 
cognitivas e lingüísticas surgem duas vezes, ou em dois planos: primeiro aparecem no plano social e, só depois, no plano individual. O desenvolvimento de qualquer capacidade individual representa um relacionamento mutável entre regulação social e auto-regulação. Daí surge o princípio educacional básico: a idéia de zona de desenvolvimento proximal.

Para VYGOTSKI (1991), a característica essencial do ensino-aprendizagem é o que se encontra na zona de desenvolvimento proximal, ou seja, o ensino volta-se não apenas para o que o aluno é capaz de fazer. Volta-se, também, para o que o aluno não é capaz de fazer a princípio, sozinho, mas pode realizar com a ajuda do adulto. Essa visão considera a etapa de desenvolvimento não mais como um ponto de chegada, mas um indicador biológico-social, que pode ser superado na interação com pessoas mais experientes.

O conceito desse desenvolvimento não pode ser separado do sistema teórico geral em que se insere. Segundo TUdGE (1996), se forem deixadas de lado as conexões entre zona e teoria como um todo, torna-se difícil diferenciar o conceito proposto nessa perspectiva de qualquer técnica instrucional que sistematicamente conduza as crianças, com a ajuda de um adulto, a progredirem na aprendizagem de um determinado conjunto de habilidades. Essa diferença é, basicamente, o contexto em que a interação ocorre.

O ensino voltado para a zona de desenvolvimento proximal é o que faz nascer, estimula e ativa na criança um grupo de processos internos de desenvolvimento no âmbito das inter-relações com os outros, sendo absorvidos e convertidos em aquisições internas das crianças (apropriação). O processo de desenvolvimento seguirá o de aprendizagem, havendo uma constante interferência de um sobre o outro.

Essa abordagem, embora também enfoque os aspectos psicológicos de desenvolvimento, concebe a educação de maneira singular. Ela não é ratificadora de processos universais de desenvolvimento. Pelo contrário, é sinônimo de movimento e está situada em determinado tempo histórico. Cada nova civilização e nova geração possui maneiras diferentes de desenvolvimento porque são produtos de toda a evolução histórica. A educação deve promover a apropriação dos conhecimentos culturais e científicos desenvolvidos até então, para que, a partir do já elaborado, possam surgir novos conhecimentos. Isso é o que faz a espécie dar novos passos, em termos de evolução.

A educação da criança não pode, portanto, ser considerada como momento apenas de desenvolvimento de conceitos espontâneos, de simples constatadora de habilidades. Para que se promova, de fato, um ensino dinâmico, que conduza não só ao domínio de habilidades rotineiras, mas à possi- 
bilidade de generalização e de abstração, é necessário dar destaque aos conhecimentos de forma sistematizada.

Evidentemente, a existência de um sistema de conceitos não é algo neutro e indiferente para a vida e a estrutura das pessoas. O conceito varia, muda por completo sua natureza psicológica quando é tomado isolado, é arrancado de um sistema. É preciso considerar o ser humano como parte de um contexto, que faz dele único. Essa unidade não está caracterizada na diferença de cor da pele, da forma dos olhos ou de quaisquer outros traços exteriores, mas sim das enormes diferenças de condições e modo de vida, da riqueza da atividade material e mental, do nível de desenvolvimento das formas e aptidões intelectuais. Esse tipo de desigualdade não depende da consciência ou da vontade dos homens. A concentração das riquezas materiais nas mãos de uma classe dominante é acompanhada de uma concentração do saber mais elaborado nas mesmas mãos, existindo uma estratificação também em termos de conhecimentos (LEONTIEV, 1978).

SAVIANI (1984) parte desse princípio para delimitar áreas de atuação pedagógicas distintas no ensino. Ele põe em evidência, a partir de uma análise sobre o movimento histórico no Brasil, a questão escolar na sociedade capitalista como objeto de disputa, dada a sua divisão em classes, com interesses opostos. Isso leva à necessidade de uma tomada de posição, em relação a uma pedagogia voltada para os interesses populares, e à necessidade de delimitar as condições concretas para a ação pedagógica, instituindo a apropriação do saber sistematizado, pelo aluno, como a mola mestra de seu desenvolvimento e, conseqüentemente, de seu espaço na sociedade.

Essa idéia persiste nas produções subseqüentes de SAVIANI (1994), quando coloca valor substancial à sistematização do saber na construção do trabalho educativo. Ele considera que o trabalho educativo deve dar condições ao indivíduo de desenvolver-se, tendo em vista não apenas o aparato biológico de que é dotado ao nascer, mas, também, por meio da apropriação do saber acumulado pelas gerações.

A questão é: a sistematização desse saber não o tem impregnado de uma ideologia dominante, branca, ocidental, considerada a partir das condições de dominação e poder de uma época? Esse é um ponto que merece atenção e cautela. Não se pode destituir a escola de seu papel histórico de impulsionadora de desenvolvimento, sobretudo cognitivo. Mas também não é possível negar que o saber por ela veiculado esteve sempre sujeito, como afirma VARELA (1994), à intervenção do poder político, direta ou indiretamente. A cada época, são estabelecidas novas relações entre saberes e poderes. A falta de criticidade e a imposição do saber por si só, como fazendo parte de um sistema neutro e 
imparcial, descolado de qualquer relação genealógica ou tendo qualquer influência nos processos sociais, foram as estratégias mais profícuas ao adestramento.

De acordo com VARELA (1994), é preciso distinguir as tendências gerais das intenções e das materializações concretas, tentando uma via de aproximação entre saberes gerais, teorias científicas e saberes locais, com o fim de inter-relacionar uns com os outros, não confundindo cultura culta com cultura dominante, buscando meios de pôr em questão a lógica crescente da pedagogização, dos esquemas classificatórios em uso, e evitando a ilusão de que o etnocentrismo das pedagogias tradicionais, seu desprezo pela cultura não acadêmica, sua rejeição à diversidade, possa se corrigir facilmente mediante a aplicação das pedagogias renovadoras. Esta última recomendação merece atenção porque, muitas vezes, a tentativa de oposição às pedagogias tradicionais pode suscitar reivindicações a uma cultura escolar excessivamente vinculada ao criativo, ao concreto e ao prático, encerrando os filhos das classes mais desfavorecidas numa espécie de realismo concreto e negando-lhes o acesso a outros tipos de saberes. Os efeitos provocados por essa atitude são os menos desejados, porque impedem que esses alunos escapem à sua condição de sujeito submetido.

Concordo com MCLAREN (1997) quando afirma que é necessário estar também atento à totalidade. Ele enfatiza que uma "rejeição a toda totalidade pode igualmente obscurecer relações, causas e conexões reais - atomizando experiências comuns em brincadeiras acidentais e infinitamente repetitivas (...) e que somente reconhecendo o legado coletivo de ações e idéias humanas acumuladas, nós podemos julgar as reivindicações de verdade e justiça de qualquer história" (p. 82). Ele justifica essa posição, citando a afirmação de BEST (1997, p. 82), segundo a qual "o reverso da tirania da totalidade é a ditadura do fragmento".

Nesse contexto, a diferença e o individual precisam ser compreendidos como contradições sociais, como diferença em relação, em vez de diferença como livre-flutuante e deslocada. O refazer social e a reinvenção do eu devem ser entendidos como dialeticamente sincrônicos e não como sem relação ou como apenas marginalmente conectados. São processos que se informam e se constituem mutuamente. 


\section{Resultados e discussão: a função social em destaque}

Os depoimentos das professoras refletiram concepções próprias de um grupo que se apropriou, ao longo de sua vida, de conceitos e valores variados. Isso reafirma a colocação de WEBER (1996), quando diz que o estudo de concepções de qualquer grupo não pode ser tomado de forma isolada. As condições político-econômicas e ideológicas devem ser consideradas, porque elas atuam sobre os indivíduos, influenciando maneiras de ser e pensar.

As professoras apresentaram uma história de vida acadêmica bem consistente. Das 15 entrevistadas, 3 (três) possuíam Curso de Pós-graduação, em nível de Especialização, 6 (seis) tinham concluído o ensino superior e 1 (uma) cursava o ensino médio. Embora a maioria tivesse origem no estrato baixo da escala de prestígio social, com pais que tinham nível de escolaridade referente ao ensino fundamental, elas, na quase totalidade, atingiram formação superior na sua área de atuação ou em áreas afins. Isso fazia com que seus discursos fluíssem com objetividade e concatenação de idéias. Além da formação superior, a experiência com alunos surdos proporcionou-lhes elementos para colocarem sua opinião no nível teórico e no prático. Por esta razão, estavam suscetíveis a assimilarem o discurso do 'politicamente correto' ou 'mais aceito socialmente e/ou teoricamente'.

Ao comentarem sobre a função da escola, as professoras mostraram uma tendência que persiste como herança de uma filosofia escolanovista que, como afirma SAVIANI (1984), apresentava uma preocupação extremada com as questões mais metodológicas (como fazer) e com o que se chamou 'função social' do ensino ou o uso dado ao conhecimento no dia-a-dia, dentro de uma perspectiva psicologizante. A inclinação de ver os fatos sob esse ângulo foi marcante nos depoimentos de nove professoras, enquanto seis consideraram a importância de trabalhar o conhecimento escolar e promover o desenvolvimento da criança.

A função social da escola foi destacada dessa maneira:

Formar cidadãos para a sociedade $\left(\mathrm{P}_{1}\right)$;

Preparar para a vida. Só que eu acho que elas não preparam muito, não $\left(\mathrm{P}_{2}\right)$;

Orientar para a vida $\left(\mathrm{P}_{3}\right)$;

Eu acho que a função da escola não é apenas passar os conteúdos pedagógicos. É preparar o indivíduo para a vida $\left(\mathrm{P}_{4}\right)$;

Fazer o trabalho educativo, mas não só de conteúdo $\left(\mathrm{P}_{7}\right)$; 
Preparar o ser humano. Acho que a escola está com uma função muito ampla, hoje, que é de preparar o ser humano para a vida. Isso na questão educacional, na da profissionalização e do social dos alunos. A escola absorveu tudo e tem mais uma função: absorveu a questão familiar, também. A escola passou a dar um apoio à criança ou ao adulto mesmo, como se fosse a família dele $\left(\mathrm{P}_{8}\right)$;

O que eu vejo é que a escola reflete muito a posição filosófica do dono. Quando é uma escola particular, isso fica claro (...) E na escola pública a gente vê que a escola retrata as pessoas que trabalham nela. Não tem um dono, mas o grupo é refletido no dia-a-dia da escola. Eu vejo a escola hoje como uma instituição que reflete o trabalho das pessoas que estão lá. Se tivesse que dar uma função à escola eu não a dividiria em pública e privada, porque eu acho que todas lidam com seres humanos. Então, se ela está lidando com esse ser, ela está lidando com um ser em crescimento, em desenvolvimento. Eu acho que a função da escola é fazer com que esse ser se aproprie dos conhecimentos, que faça com que eles se desenvolvam melhor na vida, não para a vida, mas já, enquanto ele está na escola, que tenha tudo a ver com o seu dia-a-dia. E não com aquela velha escola de preparar para o futuro. Ora, quem prepara quem para o futuro? A gente está convivendo com a vida hoje $\left(\mathrm{P}_{10}\right)$;

Um meio de integrar a pessoa à sociedade, ela não vai ficar mais restrita à família. Por meio da escola ela vai conhecendo outras famílias, vai conhecendo diversas maneiras de participar tanto do lado recreativo, como vai descobrindo várias outras atividades. Não é só o lado do professor ensinar, mas o convívio, preparando o aluno para a vida $\left(\mathrm{P}_{13}\right)$; Ela tem um papel de instruir e outro muito mais amplo, que é o papel social. Eu acho que ela deve educar, deve oferecer alternativas para o aluno ter meios de escolher melhor a profissão, não dar de bandeja, mas oferecer condições para que ele tenha essa visão ampla. A escola não deve ensinar sem saber para que vai servir isso para o aluno. A escola hoje está dividida em $1^{0}$ grau, $2^{0}$ grau, vestibular... Cada uma faz sua parte e, afinal, de contas, para que serviu esse tempo todo? Termina com as pessoas sem saberem o que a escola fez por cada uma, porque nem na profissão se usa nada do que se aprendeu. Acho que, por isso, deve-se repensar a função da escola, a sua função social $\left(\mathrm{P}_{14}\right)$.

O pragmatismo sobre a função da escola observado nesses depoimentos merece atenção porque ele, dentre outros fatores, pode influir na preparação para as aulas e nos filtros utilizados para aprofundar determinados aspectos do ensino. Esse argumento tem servido de base não só para a prática docente (o como desenvolver o ensino), mas para as explicações sobre ela (por que desenvolvê-lo dessa forma). 
Mesmo ao referirem-se ao ensino de conteúdos propriamente, pareceu haver uma necessidade de defender essa posição com expressões como "Fazer um trabalho educativo, mas não só de conteúdos", "A função da escola não é só passar os conteúdos pedagógicos" e "Não é só o lado do professor ensinar, mas o convívio, preparando para a vida".

O trabalho mais engajado ao cotidiano dos alunos foi destacado, embora uma das professoras $\left(\mathrm{P}_{8}\right)$ tenha externado preocupação com a amplitude de funções que estava sendo designada à escola. Para essa professora, a escola estava envolvendo questões de ensino, de profissionalização e também as que eram exclusivas das famílias. Mesmo entendendo essa preocupação, acredito que a abrangência de funções da escola termina sendo inevitável, porque ela reflete algumas limitações familiares. É importante, por isso, que o profissional do ensino entenda a necessidade de redimensionar seu conteúdo de ensino, levando em conta também outros componentes, não como substitutos dos conteúdos pedagógicos, porque isso faria com que a escola perdesse a verdadeira essência de seu trabalho, mas como complemento.

O ensino tradicional que procurava enfocar os conteúdos de forma neutra e imparcial e via a escola como lugar de transmissão de conhecimento estático, isento de qualquer julgamento de valores (como se isso fosse possível!) contribuiu para certo distanciamento e preconceito a quem reivindicasse uma maior atenção aos conteúdos. Muitos procedimentos educacionais passaram a cingir-se ao trabalho de conteúdo mínimo, contanto que este tivesse uso imediato no dia-a-dia.

Essa forma de agir não considera alguns aspectos básicos, sobretudo a importância de trazer o conhecimento espontâneo para o nível científico, pois é este último que vai influenciar sobremaneira na forma de o aluno elaborar e organizar seu pensamento, contribuindo para o que VYGOTSKI (1991) chama de formação de estruturas superiores de pensamento. As diligências extremadas de preparar o aluno para a vida, deixando o ensino no nível da espontaneidade, podem servir apenas para ratificar atitudes que seriam as mesmas, independentemente da existência da escola.

Se a escola tem como compromisso, como disseram algumas professoras, o desenvolvimento da criança, a preparação e a formação do ser humano, para que "se aproprie dos conhecimentos, que façam com que ele se desenvolva melhor na vida", deve evidenciar e assegurar seu espaço de sistematizadora de conhecimentos, embora procure entender as preocupações familiares e estabelecer relações educacionais mais amplas. Concordo com LIBÂNEO (1984), quando diz que a escola é socialmente necessária como lugar de instrução, onde exerce uma mediação técnica entre o aluno e a realidade 
do mundo adulto, e como meio de formação, porque exerce uma mediação sociopolítica, na medida em que veicula modelos e ideais sociais.

Isso quer dizer que o trabalho pedagógico deve tratar o conteúdo como tal, em sintonia com o mundo real, com o mundo interior, com a superação de limites, com a necessidade de abstração e com o gosto pelo estético e pelo ético. Essa idéia foi focalizada pelas demais professoras assim:

Eu acho que a escola é um local onde há uma troca de conhecimento como um todo: conhecimento de mundo, meu, do outro. Enfim, é uma troca de conhecimento e de aprendizagem $\left(\mathrm{P}_{5}\right)$;

A escola tem um compromisso com o desenvolvimento das crianças. $\mathrm{O}$ desenvolvimento não só físico, mas de responsabilidade. A escola tem que contribuir com a família para o processo educativo, para que a criança se desenvolva, tenha responsabilidade e compromisso. A escola deve contribuir com o desenvolvimento geral, em todos os níveis da criança $\left(\mathrm{P}_{6}\right)$;

Contribuir para a formação do homem. Contribuir para que o aluno conheça o mundo, possa refletir sobre ele. Enfim, contribuir para o conhecimento de uma forma geral $\left(\mathrm{P}_{9}\right)$;

Ensinar $\left(\mathrm{P}_{12}\right)$;

Para mim, a principal função da escola é garantir o processo ensinoaprendizagem $\left(\mathrm{P}_{11}\right)$;

Deveria ser para tornar as pessoas mais humanas, mais educadas, mas não acontece isso $\left(\mathrm{P}_{15}\right)$.

Essas colocações não se limitam a considerar a função imediata do conhecimento, mas a vê-lo como contributo para o desenvolvimento pleno dos alunos. Principalmente quando se faz a opção pelo trabalho no ensino público, é preciso ter em mente que a escola tanto pode exercer o papel de democratizadora, se contribuir para a transformação da situação de exclusão, como de negadora do saber, se reafirmar a condição existente. Isso depende da forma pela qual ela organiza o trabalho pedagógico. Segundo SNYDERs (1981, p. 106),

a escola é simultaneamente reprodução das estruturas existentes, correia de transmissão da ideologia oficial, domesticação, mas também é ameaça à ordem estabelecida e possibilidade de libertação. 
Este movimento conservação/transformação é próprio da dinâmica social, em que as relações entre as classes são relações de contradição e devem ser abordadas nas discussões sobre o caráter do ensino público ou privado. Exatamente por isso a escola pode traçar para si mesma uma área própria de atuação, consciente de que nem é promotora de igualdade, já que a sociedade é desigual, nem de força revolucionária, já que isso vai mais além do seu movimento possível nesta sociedade. De acordo com MELLo (1983, p. 7), para ela apreender bem seu papel, precisa "captar o movimento possível" de mudanças dentro das condições atuais.

Uma das professoras $\left(\mathrm{P}_{10}\right)$ que destacaram a função social da escola tratou sobre esse caráter público e privado. Para ela, a escola tomava a feição do grupo de professores (pública) e/ou dos dirigentes (privada), ou seja, terminava retratando esses profissionais. É bem provável que aí esteja uma das razões dos desencontros existentes. O caráter público ou privado do ensino deve ser destacado tendo em vista os/as alunos/as. É neles que os profissionais do ensino devem espelhar-se para dar forma e sentido ao conhecimento. Esse modo etnocêntrico de ensino deve ser superado para que se possa lidar com os reais interesses de cada grupo, visando a formar sociedades mais justas. $\mathrm{O}$ conhecimento e as formas de transmiti-lo não podem ser tratados com neutralidade e imparcialidade, como não o são o desenvolvimento, os interesses sociais, as aspirações e a cultura de seu corpo discente.

Não é possível deixar de chamar a atenção para a necessidade de considerar-se o tema do pluralismo cultural. Em geral, os conteúdos são selecionados e organizados segundo padrões culturais dominantes, considerados como legítimos e especialmente representativos da cultura humana (LOPES, 1997). Não é essa a idéia que defendo. Muito menos a idéia de contemplar culturas diferentes (no caso, a cultura surda) como forma apenas de reduzir preconceitos sociais, de situar a perspectiva de questionamento a visões etnocêntricas do conhecimento ou de proporcionar visões pluralistas da realidade. Defendo uma pluralidade cultural como coloca LOPES (1997), uma pluralidade de culturas e saberes com racionalidades distintas e não unificáveis.

Culturas diversas e saberes diversos precisam ser compreendidos em seus respectivos contextos histórico-sociais, constituem-se a partir de lógicas próprias e de racionalidades distintas, portanto não se submetem, de forma absoluta, uns aos outros (LOPES, 1997, p. 34). 
Acredito, assim como afirmaram algumas professoras, que esse seja o caminho para se trabalhar o conhecimento escolar e promover o desenvolvimento da criança, ao mesmo tempo em que se minimizam os vazios ideológicos, sobre a concepção de homem e mulher surdos, e os vazios epistemológicos, sobre as concepções de aprendizagem, na educação de surdos, de que trata SKLIAR (1997). De acordo com esse autor, a oposição entre sujeito normal/ sujeito deficiente impediu à educação dos surdos, particularmente, uma compreensão de teorias e de políticas educacionais mais amplas. Possibilitaria, por sua vez, a descrição da complexa natureza fragmentária e plural, que, sem dúvida, caracteriza o mundo atual onde vivem também os surdos. $\mathrm{O}$ entendimento e o engajamento no universo dos estudos educacionais pode capacitar o profissional a particularizar práticas, enriquecer o debate sobre o ensino de surdos, estabelecer as possíveis vinculações e produzir novos conhecimentos.

Quando se reportaram à escola de surdos, propriamente, quatro professoras destacaram a questão da função social e nove atribuíram várias funções à escola, ressaltando sua responsabilidade quanto à cidadania dos alunos, quanto ao trabalho com a língua de sinais e com o conhecimento escolar (conteúdo e/ou ensino-aprendizagem) e quanto à necessidade de engajar a família dos alunos no trabalho e de integrar os surdos na sociedade mais geral e na própria comunidade de surdos. Uma professora considerou que a escola devia "contribuir para a aprendizagem deles" $\left(\mathrm{P}_{15}\right)$, uma disse que não sabia qual era a função da escola de surdos $\left(\mathrm{P}_{2}\right)$ e outra colocou que a função era a mesma da escola comum $\left(\mathrm{P}_{5}\right)$.

A função social foi enfocada literalmente assim:

Maior ênfase nessa orientação para a vida, porque é na escola onde eles encontram um maior apoio. Ela (família) ou superprotege ou deixa de lado. Então, muitas vezes é na escola que eles encontram essa orientação e apoio $\left(\mathrm{P}_{3}\right)$;

Preparar a pessoa surda para a vida, para que possa trabalhar e desempenhar seu papel na sociedade. A função desta escola é a mesma de qualquer outra escola $\left(\mathrm{P}_{4}\right)$;

Eu acho que a função dela hoje é desenvolver trabalhos que tenham função social. Se a gente vai ensinar a ler e escrever, que ensine com função social; se a gente vai ensinar hábitos, atitudes, habilidades, que ensine tudo isso com uma função social. Se for só para cumprir tabela, não tem muito sentido, não $\left(\mathrm{P}_{10}\right)$;

O objetivo desta escola, acho que de todos que trabalham aqui, principalmente o meu, era que ela tivesse o objetivo maior de função 
social, como deveria ser o de qualquer escola, atingindo a família, o surdo $\left(\mathrm{P}_{14}\right)$.

Mesmo que a maioria tenha posto outros aspectos relacionados ao papel da escola de surdos, a função social do ensino ainda pareceu destacar-se das demais. Quando se trata do ensino de surdos, é preciso considerar algumas particularidades que interferem na análise sobre essa questão e que, provavelmente, foram consideradas pelas professoras entrevistadas. Devido à privação lingüística imposta aos surdos, dentro das próprias famílias, levando em conta que a maioria deles são membros de família de ouvintes, em geral não usuárias da língua de sinais, eles ingressam na escola com um pobre cabedal de conhecimento de mundo, se comparados aos ouvintes. Muitas experiências vividas pela maioria das crianças não são acessíveis à criança surda. Em decorrência desse fato, alguns estudiosos do assunto têm insistido em que as escolas de surdos proporcionem a essas crianças, desde bem pequenas ( 0 a 4 anos), o maior número de experiências com jogos, brincadeiras, passeios, dramatizações, todas respaldadas pela língua de sinais e com a presença de adultos surdos. É possível preencher essa lacuna, propiciando às crianças surdas um nível razoável de informações e de conceitos de mundo. Essa etapa é essencial para que a criança se aproprie dos significados disponíveis para ela, nos acontecimentos à sua volta. Ela pode, na sua experiência prática, dar sentido a esses significados, transformando-os, ratificando-os ou criando outros para si. VYGOTSKI (1993) considera que, nesse processo, a linguagem exerce papel preponderante.

A maioria dos alunos surdos que freqüentavam a escola, nessa época, não teve chance de se beneficiar com este tipo de trabalho. Em consequiência, havia necessidade de desenvolver com eles mais atividades que visassem a uma aplicabilidade no dia-a-dia, de um trabalho básico de apreensão dos significados. Atingir um nível razoável de compreensão sobre alguns acontecimentos, sair-se bem em algumas atividades de rotina e adquirir habilidades para desenvolver um determinado ofício a contento é, para muitos surdos, o possível nas condições atuais. A escola de surdos deve estar atenta a questões educacionais mais amplas, tendo em vista as restrições sociais e familiares e, sobretudo, o perfil de muitos surdos adultos atuais, herdeiros de um ensino oralista.

Entretanto, além dessas, outras necessidades devem emergir. É necessário que sejam criadas condições de os surdos se desenvolverem no mesmo patamar do ouvinte, promovendo atividades que priorizem os aspectos social, 
lingüístico e afetivo da criança bem pequena e o trabalho com conteúdos culturais vivos, atualizados, com os quais os alunos possam travar relação direta, para que apreendam melhor os significados presentes no mundo. Aos poucos esse conteúdo deve ser ampliado, de modo a não limitar alternativas de ação e reação dos alunos. O ensino não deve ser um caminho de direção única em que aparece só um tipo de cultura ou só uma autoridade (o professor) que domina os conteúdos. Conforme expressão de SNYDERS (1981), é um vaivém entre a continuidade vivida pela própria experiência dos sujeitos interessados e pela formação técnica e organizadora. E esse vaivém permite aos alunos ascender a níveis de conhecimentos mais elaborados, aos chamados conceitos científicos (VYGOTSKI, 1993). Só colocando todos os esforços num projeto de escola dessa envergadura pode-se quebrar o ciclo das baixas expectativas no ensino de surdos, mencionado por JOHNSON, LIDER e ERTING (1989).

Para estabelecer essas idas e vindas entre os conhecimentos espontâneos presentes no cotidiano e os conhecimentos elaborados, é preciso levar em conta também outros aspectos, como colocaram as professoras:

Integrar o surdo na sociedade, para que ele se torne, pelo menos, entendido pelos ouvintes e consiga mostrar que tem valor e que é capaz de aprender $\left(\mathrm{P}_{1}\right)$;

Favorecer o desenvolvimento do surdo em todos os aspectos e, também, passar a questão da $1^{\text {a }}$ língua, já que na família e na sociedade isso é difícil $\left(\mathrm{P}_{6}\right)$;

É fazer o mesmo trabalho que as outras escolas fazem: alfabetizar, trabalhar todos os conteúdos, nessa perspectiva de não ser só preocupado com isso. Deve procurar, também, envolver os pais $\left(\mathrm{P}_{7}\right)$;

Acho que é papel dela assumir a parte educacional, social, ela pode dar a parte de profissionalização, fazer alguns encaminhamentos. Agora, essa parte da família, a escola tomou para si esse papel, e eu acho que ela devia devolver esse papel para a família $\left(\mathrm{P}_{8}\right)$;

Teria duas coisas. Primeiro, despertar na pessoa surda que ele é um cidadão, que tem direitos e deveres na sociedade. E, segundo, está relacionado com a questão do aprendizado na escola e, nesse aprendizado, eu colocaria como função principal a importância da língua de sinais para eles (P9);

Garantir o processo ensino-aprendizagem, com a especificidade para o surdo, de integrá-lo à sociedade $\left(\mathrm{P}_{11}\right)$;

Para eles, que têm essa deficiência, para ensinar a eles, para eles aprenderem e eles crescerem principalmente na língua deles. Tentar trazer os pais para a escola. Eu acho que a função dela é abrir o que a gente faz 
tanto para os alunos, para os pais, como para a sociedade lá fora $\left(\mathrm{P}_{12}\right)$; Passar o conhecimento para eles, integrá-los na sua própria comunidade, para desenvolver a língua $\left(\mathrm{P}_{13}\right)$.

Esses fatores colocados pelas entrevistadas - trabalhar a língua de sinais, envolver os pais no trabalho e integrar os surdos à sociedade - devem permear todo o trabalho pedagógico.

O uso da língua de sinais é critério básico para esse trabalho, assim como o são as línguas orais no ensino de ouvintes. Ela não é apenas o código adequado para o estabelecimento da comunicação professor-aluno, alunoaluno, mas é a ferramenta mais importante na assimilação dos significados, na formação de sentido e na conseqüente estruturação do pensamento para os surdos. Além disso, é o meio de, por meio do entendimento da cultura de um grupo, fazer o conhecimento fluir de forma mais apropriada e contribuir para que ele seja fator de desenvolvimento não apenas individual, mas do grupo, da cultura surda. O ideal seria que existisse mais engajamento por parte da família, para que o surdo não se 'sentisse em casa' somente na escola, mas também entre seus familiares. Mas a escola não pode impor isso aos pais. Ela deve abrir espaços, com cursos e orientações, sem, no entanto, usurpar o que é de responsabilidade da família ou colocar nela a responsabilidade pelos seus insucessos. É importante que ela faça o seu papel de escola, mostre resultados práticos à comunidade, de modo a reverter a situação e adquirir mais credibilidade de todos, principalmente da família. É assim que dará sua verdadeira contribuição para a integração social, uma das funções da escola citadas pelas professoras.

\section{Considerações finais}

Pelo exposto, fica evidenciada a tendência pragmática sobre ensino na concepção das professoras entrevistadas, dificultando uma articulação no espaço escolar que supere as dificuldades atuais no ensino de surdos.

Quanto a isso, não se pode esperar fórmula mágica, nem método universal. Existem fundamentos epistemológicos gerais que podem servir de guia, de luz para a construção da prática. É fundamental que em cada situação, em cada realidade, reflita-se profundamente sobre, especialmente, quem é essa pessoa 
surda, quais suas diferenças, sobre que bases ideológicas estão sedimentadas as concepções de ensino que as tornam seres humanos na sua plenitude.

Para isso, é necessário assumir uma concepção de ensino que não se baseie na ausência, mas na afirmação de suas possibilidades, na diferença, visando a uma igualdade de oportunidades. Os profissionais da educação de surdos devem, também, ter clareza sobre a importância do aprofundamento de uma visão mais abrangente, que inclua as questões de linguagem sem superficializar sua discussão e obscurecer os verdadeiros princípios, que são sistêmicos.

\section{REFERÊNCIAS}

GALLIMORE, R.; THARP, R. O pensamento educativo na sociedade: ensino, escolarização e discurso escrito. In: MOLL, L. C. Vygotsky e a educação: implicações pedagógicas da psicologia sócio-histórica. Porto Alegre: Artes Médicas, 1996.

JOHNSON, R. E; LIDEL, S. K; ERTING, C. J. Develando los programas: princípios para un mayor logro en la educacion del sordo. Publicado pela pós-graduação em lingüística da Universidade dos Andes, Mérida, 1989.

LEONTIEV, A. N. O desenvolvimento do psiquismo. Lisboa: Horizonte Universitário, 1978.

. Uma contribuição à teoria do desenvolvimento da psique infantil. In:

VYGOTSKY, L. S.; LURIA, A. R.; LEONTIEV, A. N. Linguagem, desenvolvimento e aprendizagem. 5. ed. São Paulo: Ícone, 1988.

LIBÂNEO, J. C. A prática pedagógica de professores da escola pública. São Paulo: PUC/SP, 1984, Dissertação (Mestrado).

LOPES, A. R. C. Pluralismo cultural: preconizando o consenso ou assumindo o conflito? Revista Espaço, n. 8, p. 31-37, Rio de Janeiro, 1997.

McLAREN, P. Multiculturalismo crítico. São Paulo: Cortez, 1997.

SAVIANI, D. Escola e democracia. São Paulo: Cortez, 1984.

. Pedagogia histórico-crítica: primeiras aproximações. Campinas: Autores Associados, 1994.

SKLIAR, C. Sobre o currículo na educação de surdos. Revista Espaço, n. 8, p. 38-43, Rio de Janeiro, 1997. 
SNYDERS, G. Escola, classe e luta de classes. Lisboa: Moraes Editores, 1981.

TUDGE, J. Vygotsky, a zona de desenvolvimento proximal e a colaboração entre pares: implicações para a prática em sala de aula. In: MOLL, L. C. Vygotsky e a educação: implicações pedagógicas da psicologia sócio-histórica. Porto Alegre: Artes Médicas, 1996.

VARELA, J. O estatuto do saber pedagógico. In: SILVA, T. T. da. O sujeito da educação: estudos foucatianos. Petrópolis: Vozes, 1994.

VYGOTSKI, L. S. Obras escogidas I. Madrid: Centro de Publicações del MEC y Visor Distribuiciones, 1991.

Obras escogidas II. Madrid: Centro de Publicações del MEC y Visor Distribuiciones, 1993.

WEBER, S. O professorado e o papel da educação na sociedade. Campinas: Papirus, 1996.

Texto recebido em 07 fev. 2003

Texto aprovado em 02 jun. 2003 